\title{
Translators' Note
}

English translations of secondary sources have been silently modified in order to take into account both the original texts and Agamben's own Italian translations of these sources.

Mandelstam's poem on pages I2-I3 was translated from the Russian by Jane Mikkelson.

We would like to thank Matteo Battistini and R. Anthony Pedatella for their insights into some difficult passages. We are very grateful to Kevin Attell and Giorgio Agamben, whose generous and detailed suggestions greatly improved our translation. 

NUDITIES 
